\title{
Recursos financieros de los Gobiernos Autónomos Descentralizados: Caso de estudio Gobiernos Autónomos Descentralizados Municipales
}

Financial resources of the Decentralized Autonomous Governments: Case study Autonomous Decentralized Municipal Governments

María José Dávila mjdavila@utn.edu.ec

\author{
Gustavo Villares \\ hgvillares@utn.edu.ec
}

\author{
Marcelo Placencia (Co-Autor) \\ emplacencia@utn.edu.ec
}

\section{Resumen}

El conllevar de mejor manera la gestión de los diferentes niveles de gobierno, en la cual se tenga una relación directa con la ciudadanía, originó un nuevo modelo de asumir y ejecutar competencias. La descentralización trajo consigo una distribución diferente de recursos basada en las características propias del territorio y en la equidad, pero también dejo inmerso el trabajo continuo que los Gobiernos Autónomos Descentralizados (GAD) deben realizar para fortalecer sus capacidades institucionales y financieras. De ahí la importancia del fortalecimiento de las finanzas de los GAD a través de su gestión con enfoque en sus principales ingresos propios. El análisis cuantitativo basado en los GAD municipales refiere que si bien es cierto en el periodo entre 2006-2015 los ingresos propios han incrementado y el índice de dependencia ha ido disminuyendo paulatinamente, no obstante esta disminución es corta, debido a que el índice se sitúa en $77 \%{ }^{1}$. Es indudable que la gestión por parte de los GAD municipales en fortalecer sus finanzas se ha traducido en un incremento de recaudación por concepto de sus principales ingresos propios, es decir, los tributos (impuesto predial, patentes y activos totales), llegando a tener una mayor representatividad en relación al producto interno bruto (PIB).

\footnotetext{
${ }^{1}$ El índice de dependencia evidencia la necesidad de recursos que los GAD municipales tienen de las asignaciones del Estado.
}

Palabras Claves: Descentralización Fiscal, Gobiernos Autónomos Descentralizados y Finanzas Públicas, Competencias.

\section{Abstract}

The better management of the different levels of government, in which there is a direct relationship with citizens, led to a new model of assuming and executing competencies. Decentralization brought a different distribution of resources based on the characteristics of the territory and on equity, but it also left a continuous work that the Decentralized Autonomous Governments (GAD) must carry out to strengthen their institutional and financial capacities. Hence the importance of strengthening the finances of the GAD through its management with a focus on its main own income. The quantitative analysis based on the municipal GAD states that although it is true that in the period between 2006-2015 its income has increased and the dependency index has been gradually decreasing, however this decrease is short, because the index is located in $77 \%$. Undoubtedly, the management by the municipal GADs in strengthening their finances has resulted in an increase in collection for their main own income, that is, taxes (property tax, patents and total assets), reaching a greater representation in relation to gross domestic product (GDP). 
Economía y Negocios UTE, V. 9-N2, Dec. 2018, pp. 65-82 https://revistas.ute.edu.ec/index.php/economia-y-negocios ISSN-E: 2602-8050 / ISSN-L: 1390-6674
Recibido (Received): 2018/09/04

Aceptado (Acepted): 2018/10/01

$\mathrm{CC}-\mathrm{BY}$

Keywords: Fiscal Decentralization, Decentralized Autonomous Governments (DAG) and Public Finances and Competencies. 


\section{INTRODUCCIÓN}

A partir de la Constitución de la República del Ecuador de 2008, los distintos niveles de gobierno (provincias, municipios y juntas parroquiales), son reconocidos como Gobiernos Autónomos Descentralizados y en base al Código Orgánico de Organización Territorial, Autonomía y Descentralización de 2010 (COOTAD), queda implementado la normalización de un nuevo modelo de descentralización que transfigura: a) lo individualista y excluyente (a la carta y uno a uno) en solidario e incluyente (obligatorio y progresivo); b) competencias difusas $\mathrm{y}$ sobrepuestas a un sistema de competencias exclusivas por nivel de gobierno; c) procesos de transferencia de competencias sin recursos a un proceso con costeo de competencias; d) prácticas clientelares en la asignación de recursos a un modelo de equidad territorial. $\mathrm{Si}$ bien es cierto, los recursos financieros percibidos por los GAD han existido siempre; sin embargo, el cambio estructural desde el año 2010 dio un giro total a la distribución y gestión de los mismos. Como primer mecanismo de percepción de recursos, los GAD participan de las rentas del estado de conformidad con los principios de subsidiariedad, solidaridad y equidad territorial, principios que han sido traducidos en: a) transferencias por el modelo de equidad territorial; b) transferencias por nuevas competencias y c) transferencias para compensar a los GAD en cuyos territorios se generen, exploten o industrialicen recursos no renovables. Como segunda instancia, se encuentran los ingresos propios provenientes de las gestión interna de los GAD, y por último, pero no menos importante, se encuentran los empréstitos o financiamiento.

Al centrar el estudio del nuevo modelo de descentralización territorial en los GAD Municipales se puede observar que son el nivel de gobierno que mayor ingreso percibe, ya sea por las transferencias del Estado o porque poseen mayor facultad tributaria, traducida en mayor generación de ingresos propios. Sin embargo la dependencia de recursos ajenos a su gestión es alta, entonces, ¿cómo fortalecer sus finanzas y lograr incrementar sus ingresos propios? En la presente investigación se pretende elucubrar piezas claves de la gestión tributaria de los GADM con el fin de fortalecer poco a poco sus finanzas, considerando que ninguna receta descrita será la panacea ni tampoco la dependencia de los recursos estatales desaparecerá.

\section{MATERIALES Y MÉTODOS}

Para el desarrollo del contenido se conjuga la investigación bibliográfica y la investigación descriptiva, partiendo de las bases fundamentales de la generación de recursos financieros, la composición de los mismos para determinar las potencialidades recaudatorias. En este contexto el fin último será la búsqueda de alternativas que permitan fortalecer las finanzas de los GAD municipales a través de sus ingresos propios.

\section{El principio de descentralización}

La visión de descentralización parte de generar una nueva estructura de organización y administración del Estado, cuyo propósito es acercar la administración púbica a los ciudadanos para lograr una mayor participación en la toma de decisiones que en mediano y largo plazo permita subsanar deficiencias y problemáticas que aquejan al territorio, todo esto en pro de una mejor calidad de vida (Senplades, 2014).

El Plan Nacional de Descentralización de 2012-2015 enfatiza la búsqueda del nuevo modelo de descentralización en promover un ordenamiento territorial equitativo, que permita la conjunción y armonice las actividades socioculturales, administrativas, económicas y de gestión que impulsen la unidad del Estado y fortalezcan el régimen económico popular y solidario garantizando una mejor calidad de vida.

La Constitución del 2008 marca la pauta en la cual descentralización debe enmarcarse en los principios de justicia económica, subsidiaridad y solidaridad en territorio, generando un proceso obligatorio y progresivo a través de la asignación de responsabilidades 
y atribuciones efectuadas, mediante la transferencia de competencias a cada nivel de gobierno, delimitando su rol y ámbito de acción (Bedón y Guerra, 2012).

Acorde al COOTAD 2016, el establecimiento neto de la nueva estructura territorial parte de tres dimensiones: política, fiscal y administrativa.

\section{Descentralización fiscal}

El proceso de descentralización fiscal, desde sus inicios, busca procurar la equidad en la asignación de los recursos, eficiencia en el destino de los recursos públicos y endeudamiento responsable tomando como base dos principios fundamentales: la equidad interterritorial y la solidaridad. El énfasis de este contexto va dirigido a la importancia de prestación de bienes y servicios públicos a la población en los diferentes niveles de gobierno (Senplades, 2014).

\section{Recursos financieros de los GAD}

Acorde a lo establecido en la Constitución de 2008, los GAD, como parte del Estado y bajo principios de subsidiariedad, solidaridad y equidad territorial, tienen derecho a participar de los ingresos o rentas percibidas por el Gobierno Central; de forma simultánea generarán su propios recursos financieros a utilizarse sostenible, responsable y transparentemente con el objeto de alcanzar el buen vivir de su población. En concordancia a lo citado los GAD están en la obligación de aplicar procedimientos que permitan el acceso a la información, rendición de cuentas, control público y transparencia de los recursos económicos públicos que hayan recibido, transferido o recaudado (COOTAD, 2010).

\section{Figura 1. Recursos financieros de los Gobiernos Autónomos Descentralizados}

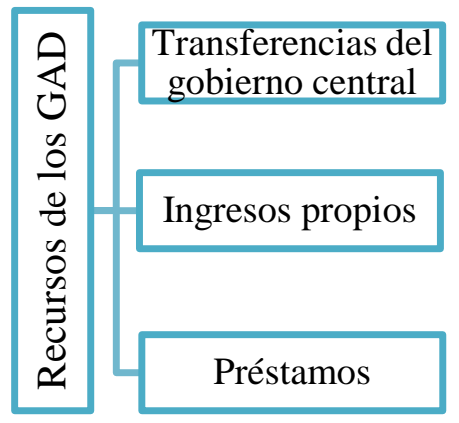

Fuente: COOTAD, 2016

\section{Transferencias del gobierno central}

Como aporte al fortalecimiento de las finanzas subnacionales, el Estado asigna determinados montos de dinero en función a características propias de cada circunscripción territorial. A partir del año 2010, se derogan aproximadamente 17 leyes que distribuían los recursos con dedicación, dando lugar a transferencias específicas enfocadas en cubrir las verdaderas necesidades de todos los habitantes del Ecuador (Bedón y Guerra, 2012). a. Modelo de equidad territorial

El objetivo de las transferencias, por el modelo de equidad territorial, es garantizar la provisión equitativa de bienes y servicios públicos relacionados con las competencias exclusivas que cada nivel de gobierno autónomo descentralizado, a todos los ciudadanos y ciudadanas del país, independientemente del lugar de su residencia, para lograr equidad territorial (COOTAD, 2016). 
El monto del cual se distribuyen los recursos destinados a los GAD proviene del $21 \%$ de los ingresos permanentes y el $10 \%$ de los ingresos no permanentes del presupuesto general del Estado. A partir de la distribución señalada y acorde a las competencias que cada nivel de gobierno debe ejecutar los porcentajes de asignación son: 27\% para los GAD provinciales, $67 \%$ para los GAD municipales y $6 \%$ para los GAD parroquiales rurales.

\section{Figura 2. Modelo de equidad territorial}

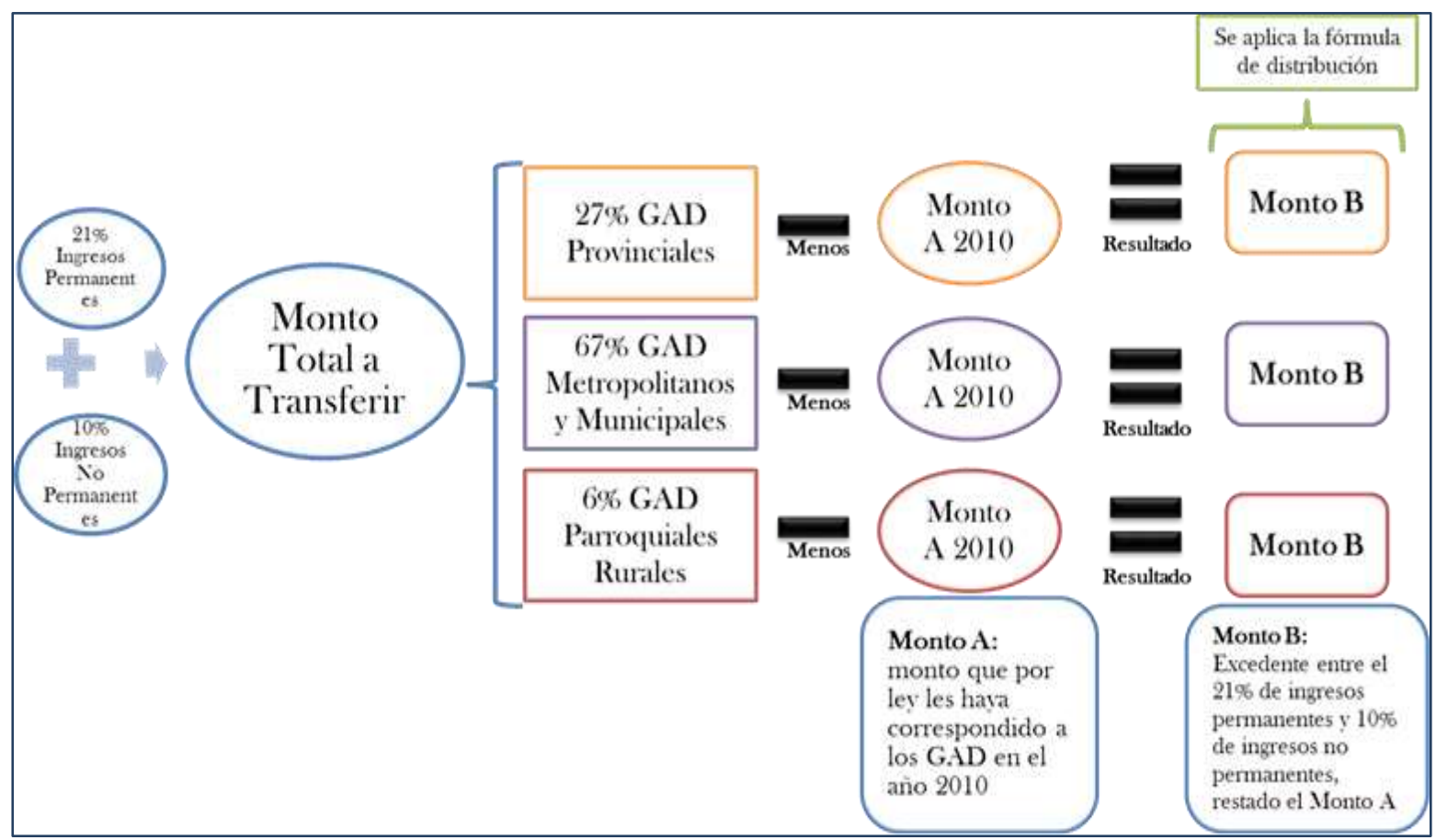

Fuente: COOTAD, 2016

Es importante mencionar que existen también diversas ponderaciones de asignaciones acordes a la residencia de la población dentro de cada uno de los GAD. La transferencia por modelo de equidad territorial

\footnotetext{
${ }^{2}$ Los criterios de asignación para los GAD provinciales y municipales son 7 mientras que para los GAD parroquiales rurales son 6 debido a que no se calcula el
}

En función a estos porcentajes se considera para efecto de los mismos el monto A y monto B. Monto A como el COOTAD (art. 193) lo establece deberá ser el mismo que los GAD recibieron en el año 2010, mientras que el monto B tiene varios criterios ${ }^{2} \mathrm{de}$ asignación: tamaño de la población, densidad de la población, necesidades básicas insatisfechas, logros en el mejoramiento de los niveles de vida, esfuerzo fiscal, esfuerzo administrativo y cumplimiento de metas. 
50\% más (COOTAD, 2016) y el área insular acorde a la Ley Orgánica de Régimen Especial de la Provincia de Galápagos, art. 196, se lo calculará multiplicando el índice de precios anual al consumidor con respecto a los precios del Ecuador continental.

A partir del año 2014, la economía ecuatoriana fue golpeada con la disminución del precio del barril de petróleo, colocándose en el año 2016 en USD 26,50 dólares, fenómeno que causó la contracción de los ingresos no permanentes del Estado, ante ello el Ministerio de Finanzas con respaldo en la Ley Orgánica para el Equilibrio de las Finanzas Públicas, establece mediante acuerdos el monto de la transferencia a ser destinada a cada GAD. Monto que será revisado cuatrimestralmente y responderá a la recaudación efectiva de los ingresos permanentes y no permanentes percibidos por el Estado. En este sentido con base en el primer cuatrimestre del año 2017 y mediante Acuerdo N. ${ }^{\circ} 0005$ se establece los montos a ser transferidos.

\section{Tabla 1. Transferencias por el Modelo de Equidad Territorial Cuatrimestre 2017 \\ (Cifras en dólares)}

\begin{tabular}{|c|r|r|}
\hline Concepto & Asignación inicial & $\begin{array}{l}\text { Estimación con base en } \\
\text { recaudación efectiva del } \\
\text { 1er.cuatrimestre }\end{array}$ \\
\hline $\begin{array}{c}\text { Ingresos permanentes del PGE para } \\
\text { distribuir }\end{array}$ & $13.389 .674 .520,00$ & $12.526 .249 .962,08$ \\
\hline $\begin{array}{c}\text { Ingresos no permanentes del PGE para } \\
\text { distribuir }\end{array}$ & $500.000 .000,00$ & $903.954 .649,30$ \\
\hline $21 \%$ Ingresos permanentes & $2.811 .831 .649,20$ & $2.630 .512 .492,04$ \\
\hline $10 \%$ Ingresos no permanentes & $50.000 .000,00$ & $90.395 .464,93$ \\
\hline Total a distribuir de ingresos & $\mathbf{2 . 8 6 1 . 8 3 1 . 6 4 9 , 2 0}$ & $\mathbf{2 . 7 2 0 . 9 0 7 . 9 5 6 , 9 7}$ \\
\hline
\end{tabular}

Fuente: Acuerdo 0005 del Ministerio de Finanzas, mayo 2017.

Elaborado por: Autores

\section{competencias}

El objeto de estas transferencias es garantizar que los GAD asuman nuevas competencias que estaban siendo desarrolladas por el gobierno central. Estas transferencias serán financiadas con los mismos recursos que el gobierno central ha destinado históricamente para el ejercicio de estas competencias, calculado con base en el

promedio de los últimos cuatro años. Los recursos por nuevas competencias deberán ser utilizados para financiar el ejercicio y no podrá duplicarse ni generar pasivos adicionales al gobierno central (COOTAD, 2016). Las competencias transferidas al 2017 han sido:

\section{8-CNC-2012)}

La competencia constitucional de planificar, construir, operar y mantener sistemas de riego como de drenaje, se encuentra asignada a los gobiernos autónomos descentralizados provinciales. En tal virtud, estos deberán elaborar y ejecutar plan de riego de su circunscripción territorial de conformidad con las políticas de desarrollo 
rural territorial $\mathrm{y}$ de fomento productivo, agropecuario y acuícola que se establezcan.

El monto transferido por esta competencia debe responder a la contraprestación de proyectos de inversión para riego y drenaje, la metodología de distribución es:

Un monto fijo para todos los GAD provinciales, equivalente al $35 \%$ del monto total.

$\checkmark \quad$ Un monto para riego equivalente al $60 \%$ del monto total.

$\checkmark \quad$ Un monto para drenaje equivalente al $5 \%$ del monto total.

La distribución y asignación de cada monto antes señalado se los efectúa de la siguiente forma:

El factor de distribución para la competencia de riego y drenaje son las hectáreas agrícolas comprendidas por cultivos permanentes, transitorios, barbecho, descanso y pasto cultivados, tomando en cuenta que se excluyen: pastos naturales, páramos, bosques y otros usos.

\section{- Tránsito, transporte terrestre y seguridad vial. Resolución 006-CNC- 2012}

El ejercicio de la competencia, en el marco del plan de ordenamiento territorial de cada territorio se desarrollará de la siguiente forma:

A los GAD municipales les corresponde de forma exclusiva planificar, regular y controlar el tránsito, el transporte y la seguridad vial, dentro de su territorio.

$\checkmark \quad$ La rectoría general del sistema nacional de tránsito, transporte terrestre y seguridad vial corresponderá al Ministerio rector.

Los valores a ser distribuidos por concepto de esta competencia, corresponde al valor recaudado por los GAD municipales y las entidades del gobierno central, por concepto del cobro de la tasa de matriculación y sus multas asociadas. Estos rubros a su vez son distribuidos de la siguiente manera:

Del monto total de tasas de matriculación y multas asociadas, se asigna un monto por concepto de costos fijos mínimo de la competencia de acuerdo a cada modelo de gestión. En este contexto, el monto fijo para los GAD municipales cuyo modelo de gestión es A y B es de USD 50000.

$\checkmark \quad$ El valor restante entre el monto total a distribuir y el monto fijo asignado a cada GAD, se denomina monto variable que es distribuido a los GAD municipales.

$\checkmark \quad$ En aquellos GAD municipales en los que el gobierno central realice el control operativo de tránsito, del monto variable distribuido se asignará al gobierno central el $51,7 \%$.

Los criterios de distribución pertinentes a la competencia son población (30\%), participación de la población urbana en la población total (10\%), tasa de motorización $(40 \%)$, densidad y dispersión poblacional (20\%), kilómetros de las vías urbanas (0\%) y esfuerzo fiscal-administrativo (0\%); y el factor de distribución es el número de vehículos existentes en cada GAD municipal.

\section{- Preservar, mantener y difundir el patrimonio cultural Resolución 004-CNC-2015}

Corresponde a los GAD municipales formular, aprobar, ejecutar y evaluar los planes, programas y proyectos destinados a la preservación, mantenimiento y difusión del patrimonio arquitectónico, cultural y natural, de su circunscripción y construir los espacios públicos para estos fines.

Para efecto, el patrimonio en referencia será considerado con todas las expresiones tangibles e intangibles. La preservación abarcará el conjunto de acciones que permitan su conservación, defensa y protección; el mantenimiento y difusión del patrimonio arquitectónico, cultural y natural, de su circunscripción y construir los espacios públicos para estos fines.

La distribución de recursos correspondiente a la competencia de patrimonio, se las realizará en función de tres ítems:

$\checkmark \quad$ Monto por densidad patrimonial $(40 \%)$. 
$\checkmark \quad$ Monto por capacidad operativa (30\%).

$\checkmark \quad$ Monto por recursos relacionados $(30 \%)$, se destina de forma inversa.

Para los GAD municipales que recibían igual o mayor a USD $1000 \quad 000$, la transferencia por competencia de patrimonio no será distribuida para ellos.

\section{c. Explotación e}

industrialización de recursos no renovables

Los ingresos percibidos por los gobiernos autónomos descentralizados por explotación de recursos naturales no renovables tienen como propósito compensar los efectos negativos de la explotación y la disminución del patrimonio natural. Las leyes que permanecen en vigencia son la Ley 010 del Fondo para el Ecodesarrollo Regional Amazónico y de Fortalecimiento de sus Organismos Seccionales y la Ley 047 de Asignaciones para Provincias por Venta de Energía de INECEL (COOTAD, 2016).

\section{- $\quad$ Ley 010 - Ecodesarrollo}

El fondo de ecodesarrollo regional amazónico, está integrado por los ingresos provenientes de un impuesto aplicado a cada barril de petróleo que se extraiga en la región amazónica y se comercialice en los mercados internos y externo que equivale a un dólar por barril. Los recursos distribuidos por este fondo corresponden a:

$58 \%$ para los GAD municipales amazónicos, incluidos los GAD parroquiales rurales de Río Verde y Río Negro del Cantón Baños; y los GAD parroquiales rurales de Matus, El Altar, La Candelaria y Bayusig del Cantón Penipe.

$\checkmark \quad 28 \%$ para los GAD provinciales de la región amazónica.

9\% para el Fondo regional amazónico cuya administración está a cargo del Instituto para el Ecodesarrollo Regional Amazónico.

$\checkmark \quad 5 \%$ para la creación del Fondo de Desarrollo Parroquial Amazónico.

\section{- $\quad$ Ley 047}

Esta ley estableció la asignación del 5\% de la venta de energía originada en las centrales hidroeléctricas de Paute, Pisayamba y Agoyán en beneficio de las provincias de Azuay, Cañar, Morona Santiago y Tungurahua a partir de 1990. La forma de distribuir los recursos por la ley 047 se base en:

\section{- Central hidroeléctrica de Paute}

- $\quad$ El $60 \%$ se distribuye en partes iguales entre los GAD municipales de Azuay, Cañar y Morona Santiago, que los utilizarán exclusivamente para realizar obras de infraestructura.

- EL $40 \%$ es asignado al Centro de Reconversión Económica del Azuay, Cañar y Morona Santiago, que deberá invertir el $80 \%$ para la ejecución de obras y el $20 \%$ para programas de forestación y reforestación del río Paute.

\section{- Central hidroeléctrica de Pisayamba y Agoyán}

- El $40 \%$ es destinado al Consejo Provincial de Tungurahua, para ser utilizado en obras de saneamiento ambiental y caminos vecinales de las zonas rurales de la provincia $y$ programas de forestación $y$ reforestación.

- El $40 \%$ se distribuye en partes iguales entre los municipios de Tungurahua, excepto el de Ambato, para ejecución de obras de infraestructura.

- El 20\% es asignado al Municipio de Ambato con el fin de invertir en obras de agua potable, canalización, caminos y obras de carácter infraestructural.

\section{Ingresos propios de los Gobiernos Autónomos Descentralizados}

Amparados en la normativa vigente y con base en la gestión a desempeñar de los GAD, acorde a las competencias designadas, los niveles de gobierno deberán generar ingresos destinados a ejecutar que obras que permitan beneficios claros y concretos para la 
ciudadanía, logrando así mejorar la calidad de vida de cada uno de los pobladores que residen en su circunscripción territorial. La efectividad de estos ingresos se la realizarán a través de ingresos tributarios y no tributarios.

\section{a. Ingresos tributarios}

Al estudiar el desarrollo del sistema tributario es imperante revisar literatura que direcciona la aplicación y comportamiento del mismo. Si bien existen varias aristas que han confluido para la admisión de diferentes principios que autores con base en su coyuntura identificaron.

\section{Cuadro 3. Principios del sistema tributario}

\begin{tabular}{|c|c|c|c|}
\hline Adam Smith & Adolfo Wagner & $\begin{array}{c}\text { Harold M. } \\
\text { Sommers }\end{array}$ & Fritz Neumark \\
\hline $\begin{array}{l}\text { An inqury into he } \\
\text { nature and causes of } \\
\text { the Wealth of Nations }\end{array}$ & $\begin{array}{l}\text { Finanzwissenschaft: die britische } \\
\text { und französische besteuerung in } \\
\text { ihrer neuesten entwicklung und } \\
\text { gestaltung }\end{array}$ & $\begin{array}{l}\text { Finanzas Públicas e } \\
\text { Ingreso Nacional }\end{array}$ & Principios de la imposición \\
\hline $\begin{array}{l}\text { Principios elementales } \\
\text { de la normativa jurídica } \\
\text { - tributaria } \\
\text { - Justicia o } \\
\text { proporcionalidad } \\
\text { - Certidumbre o } \\
\text { Certeza } \\
\text { - Comodidad } \\
\text { - Economía }\end{array}$ & $\begin{array}{l}\text { Principios elementales de las } \\
\text { finanzas } \\
\text { - Suficiencia de la } \\
\text { imposición } \\
\text { - Elasticidad o movilidad } \\
\text { de la imposición } \\
\text { - Buena fuente de } \\
\text { impuestos } \\
\text { - Elección de clases de } \\
\text { impuestos } \\
\text { - Generalidad } \\
\text { uniformidad } \\
\text { - Fijeza de la imposición } \\
\text { - Comodidad de la } \\
\text { imposición } \\
\text { - Reducción de los gastos } \\
\text { de recaudación. }\end{array}$ & $\begin{array}{l}\text { Principios } \\
\text { elementales de la } \\
\text { finanzas públicas } \\
\text { • Capacidad } \\
\text { de pago } \\
\text { - El } \\
\text { beneficio } \\
\text { - Crédito por } \\
\text { ingreso ganado } \\
\text { - Ocupación } \\
\text { plena } \\
\text { • Convenien } \\
\text { cia }\end{array}$ & $\begin{array}{l}\text { Fines determinados que surgen de } \\
\text { la orientación política y } \\
\text { económica } \\
\text { - Presupuestarios-fiscales } \\
\text { de la imposición } \\
\text { - Políticos sociales-éticos } \\
\text { de la imposición } \\
\text { - Redistribución fiscal de } \\
\text { la renta y riqueza } \\
\text { - Jurídicos-tributarios y } \\
\text { técnicos-tributarios }\end{array}$ \\
\hline
\end{tabular}

Fuente: An inqury into he nature and causes of the Wealth of Nations (1776); Finanzwissenschaft: die britische und französische besteuerung in ihrer neuesten entwicklung und gestaltung (1886); Finanzas Públicas e Ingreso Nacional; Principios de la Imposición (1994).

Con énfasis en lo señalado, en el Ecuador, los ingresos tributarios se consideran recursos económicos que los GAD perciben por la aplicación — mediante ordenanza - de impuestos, tasas y contribuciones especiales de mejoras (CEM).

\section{b. Ingresos no tributarios}

Como complemento a las finanzas subnacionales se encuentran ingresos económicos que responden a varias actividades como rentas patrimoniales, transferencias y aportes (asignaciones fiscales, asignaciones de entidades autónomas, descentralizadas o de otros organismos públicos y transferencias en el exterior), venta de activos e ingresos varios (COOTAD, 2016).

\section{Empréstitos o financiamiento}

Los GAD, para financiar inversiones de mediano y largo plazo que no puedan ser cubiertas con sus recursos pueden acceder al endeudamiento nacional como internacional. Sin embargo los ingresos generados por este mecanismo deberán ser destinados únicamente a financiar egresos no permanentes, es decir proyectos de mediano y largo plazo 
priorizados en sus planes de desarrollo (COOTAD, 2016).

\section{Resultados y discusión}

En relación a las finanzas de los $\mathrm{GAD}$, es importante la gestión que cada uno de los niveles de gobierno debe realizar para obtener ingresos propios que les permitan cubrir las necesidades imperantes de su circunscripción. Con respaldo en la normativa vigente son los Gobiernos Autónomos Descentralizados Municipales quienes poseen mayor capacidad de recepción de recursos económicos propios debido a las atribuciones tributarias establecidas (COOTAD, 2016).

En este contexto se procede a realizar un análisis descriptivo que permita evidenciar como están distribuidas las finanzas de los GAD municipales, es decir con qué tipo de ingresos cuenta mayoritariamente para la ejecución de su presupuesto. El desarrollo de estudio se basa en una investigación cuantitativa cuya data proviene del agente de los municipios y se recoge en bases del Ministerio de Finanzas.

\section{Dependencia financiera}

Al identificar el porcentaje de representación que el Estado mantiene en territorio a través de los recursos económicos distribuidos a títulos de transferencias se determina la espera de los GAD en percibir recursos que por ley el Gobierno debe transferir sin considerar realizar la recaudación de mayores ingresos que surjan de su gestión, de su interés por ejecutar de manera eficiente las competencias asignadas (SENPLADES, 2014). Para efectuar el cálculo se emplea el índice de dependencia.

Transferencias del Estado

$\overline{\text { Ingresos propios - financiamiento }}$

En el periodo comprendido entre 2006 y 2015 la evolución de la dependencia financiera ha tenido varias oscilaciones y es en el año 2015 en donde se evidencia un decrecimiento bastante pronunciado con respecto al año 2014. Los motivos pueden ser varios, por ejemplo:

- La disminución en los ingresos no permanentes del Estado por la caída del precio del petróleo, originando regulaciones en las cuentas y por ende disminuyendo el monto de transferencias destinadas a los GADM.

- Mayor gestión de los GADM para recaudar recursos económicos.

- El financiamiento otorgado a este nivel de gobierno disminuyó.

En este contexto el índice de dependencia en promedio disminuyó situándose en $77 \%$, es decir que la administración de los cantones se la realizó básicamente con los recursos económicos transferidos, sabiendo que el destino de las transferencias deben respetar la regla fiscal de hasta el 30\% para cubrir gastos permanentes y mínimo un $70 \%$ para cubrir gastos no permanentes.

\section{Gráfico 1. Dependencia financiera}


Periodo 2006-2015

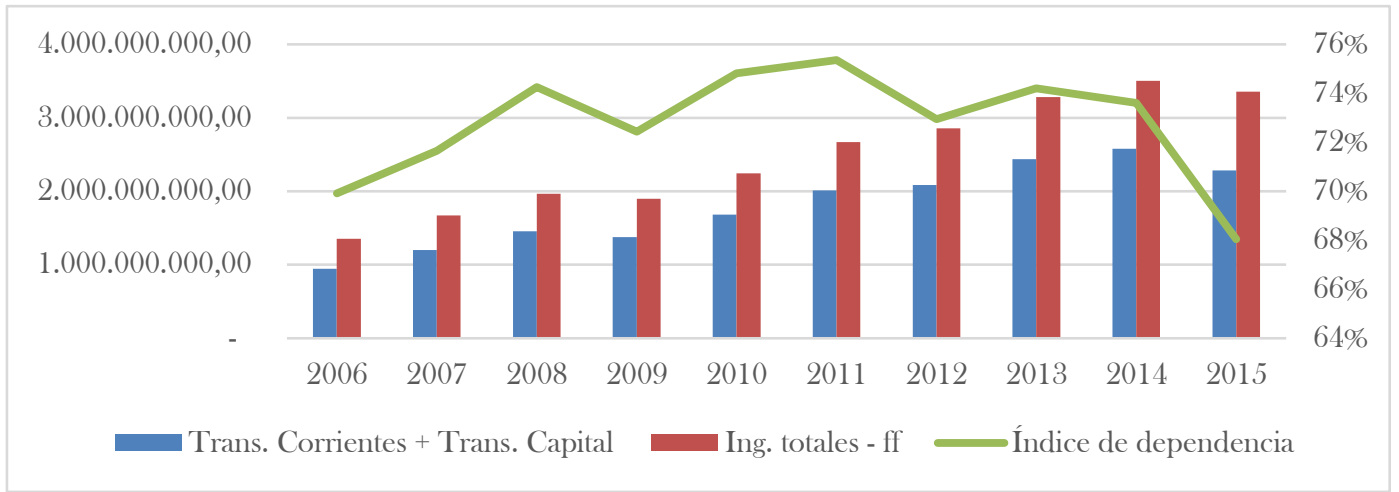

Fuente: Ministerio de Finanzas, 2006-2015.

Elaboración: Autores

\section{Ingresos propios gestionables}

Acorde a la clasificación de recursos financieros de los GAD municipales, los ingresos propios tienen un porcentaje de representación en la ejecución presupuestaria del año 2015 del 32\%, y considerando el periodo de estudio 2006-2015, se sitúa en $23 \%$. La composición de estos recursos financieros parte de dos grandes grupos: tributarios y no tributarios, los mismos que por su esencia llevan la distinción de ser ingresos permanentes y no permanentes, respaldando así la representación que cada uno de ellos tienen en la gestión de los municipios. En concordancia, de USD 1072 millones de dólares que en el año 2015 este nivel de gobierno percibió por concepto de ingresos propios, el $82 \%$ corresponde a ingresos tributarios de los cuales el $61 \%$ pertenece a la recaudación de impuestos. Siguiendo el hilo conductor de análisis, en el periodo 20062015, de un promedio de USD 675 millones de ingresos propios, el $79 \%$ pertenece a ingresos tributarios de los cuales, el 54\% responde a la recaudación de impuestos.

\section{Gráfico 2. Composición de ingresos municipales}

Periodo 2006-2015

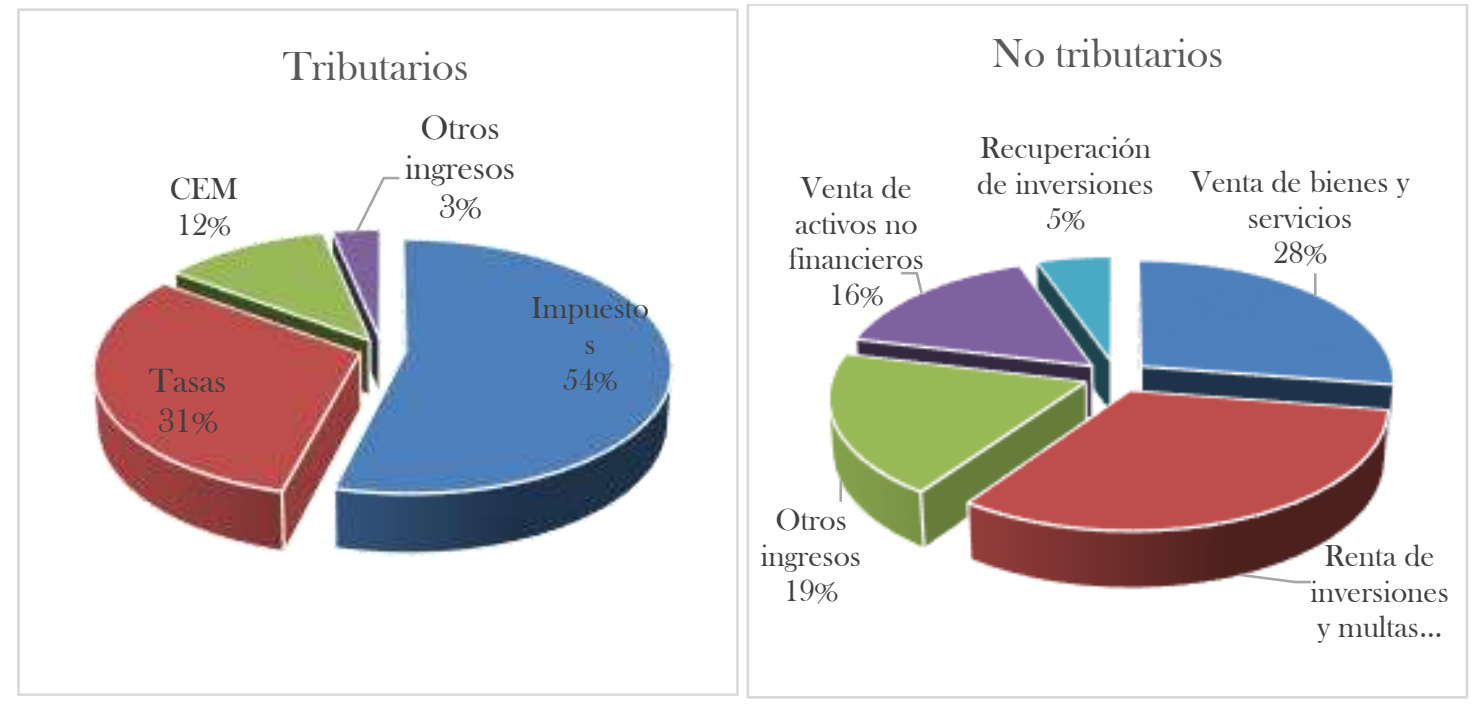

Fuente: Ministerio de Finanzas, 2006 - 2015

Elaboración: Autores 
Una vez identificado a los impuestos como los tributos que mayores ingresos les proporciona a los GAD municipales es importante analizar la concepción de los mismos, con el fin de priorizar las acciones que permitan el fortalecimiento de las finanzas dependiendo cada vez menos de los recursos destinados por parte del Estado. Considerando que los principales impuestos responden a los direccionados a la riqueza (entendida como impuesto predial) y a las actividades económicas (patentes y activos totales) es esencial conocer, desde su determinación, su gestión y el impacto que su recaudación puede llegar a tener en el desarrollo de las ciudades.

\section{Gráfico 3. Composición de impuestos municipales a nivel nacional}

\section{Periodo 2006-2015}

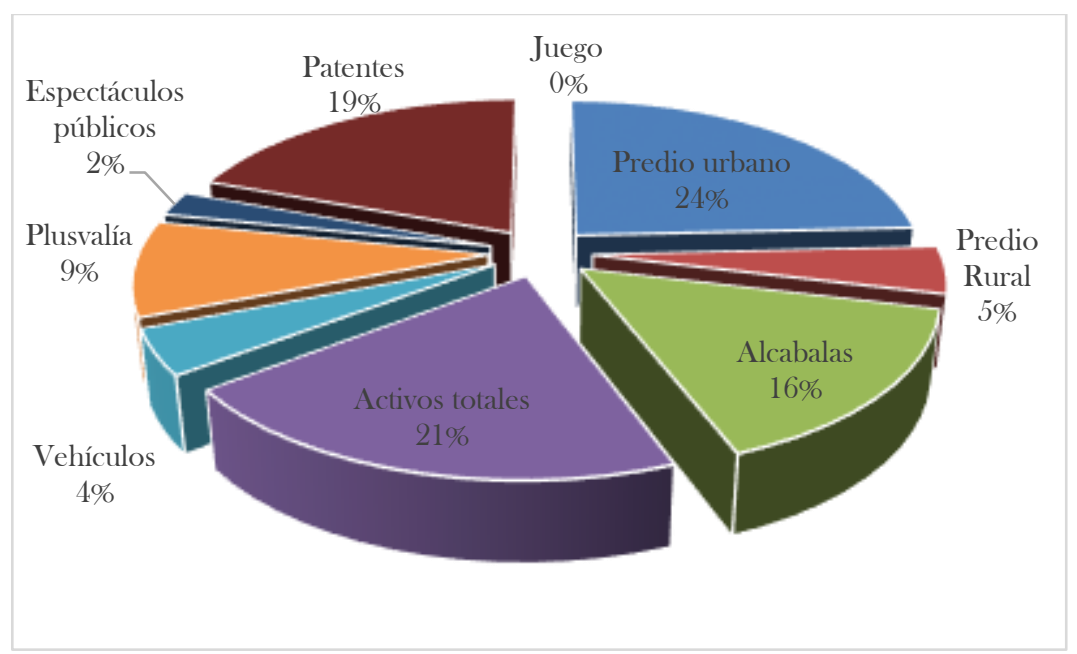

Fuente: Ministerio de Finanzas, 2006 - 2015.

Elaboración: Autores

\section{Impuestos estrellas en las finanzas de los GAD municipales}

La denominación de impuestos estrellas, surge de la evidencia cuantitativa que muestra al impuesto predial (urbano y rural) a patentes $\mathrm{y}$ activos totales como los tributos que mayor recaudación tiene en los cantones. La distinción de la representatividad de los impuestos antes mencionados dependerá básicamente de las características propias de cada circunscripción territorial.

\section{Gestión tributaria del Impuesto predial}

El tema que atañe la gestión del impuesto predial nace desde el mantenimiento $o$ actualización catastral para llegar a su determinación (hecho generador, base imponible, exenciones o deducciones, emisión, recargos, facturación) y en lo posterior a la recaudación (estrategia de cobranza, descuento por pronto pago y gestión social).

En conjunción de todas las etapas del proceso descrito, la presión fiscal del impuesto predial en relación al PIB en el periodo comprendido de 2010-2015 (Gráfico 4) ha tenido varias oscilaciones, las más relevantes con tendencia a crecimiento van desde el 2011 al 2013, y en el año 2015 comienza el despunte de crecimiento llegando a representar la recaudación del impuesto predial a nivel de país el 0,13\% del total del PIB. 


\section{Gráfico 4. Presión fiscal impuestopredial/ PIB}

2010-2015

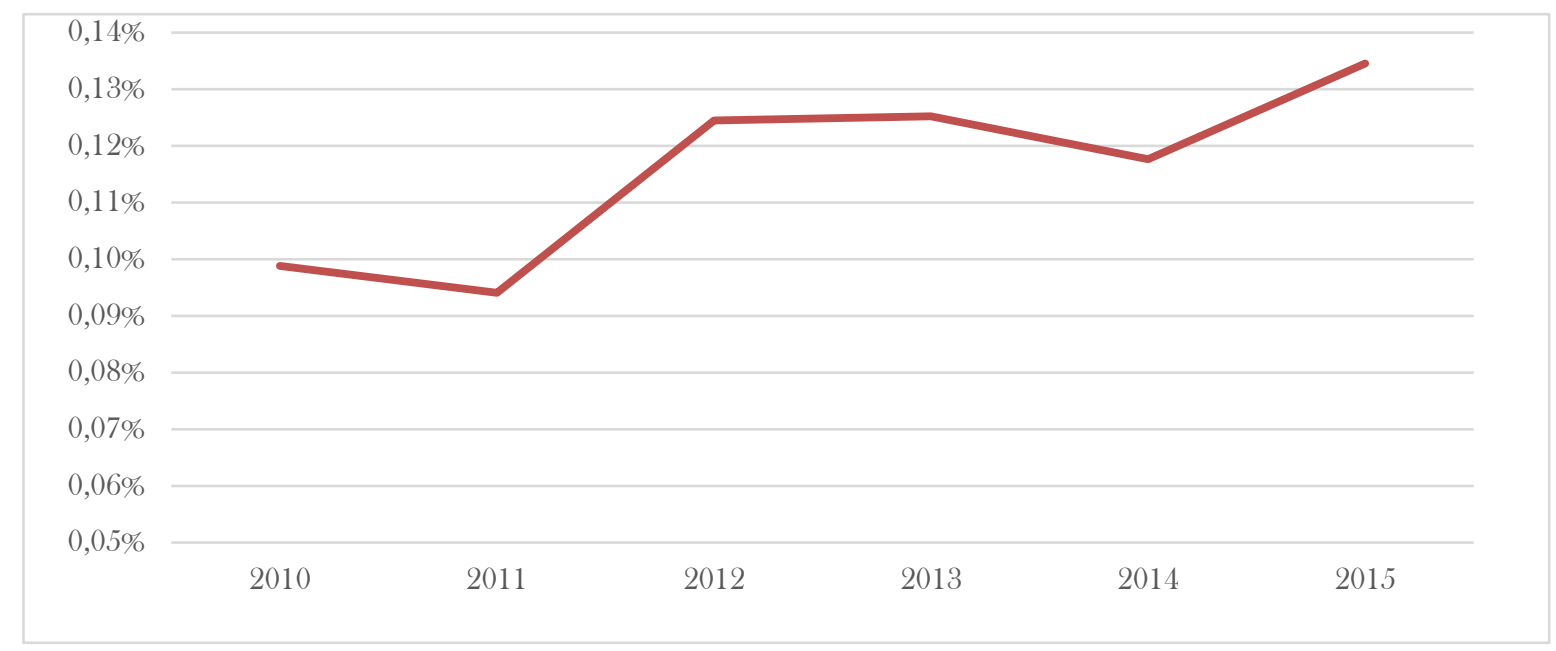

Fuente: Ministerio de Finanzas, Banco Central del Ecuador, 2006 - 2015.

Elaboración: Autores

En referencia a las variaciones sufridas en los años de estudio se puede considerar varias causas que han generado las diferentes oscilaciones, algunas de ellas son:

-El incremento en la recaudación del impuesto predial, lo cual se traduce en un mejoramiento de las estrategias de recaudación, de cobranza y gestión social que los GAD municipales han implementado.

- La disminución del PIB cantonal que decanta en decrecimiento de la producción de bienes y servicios en las circunscripciones territoriales municipales.

Acorde a la evidencia empírica (Gráfico 5), se determina que desde el año 2011 al 2013 existió incremento en la producción de bienes y servicios de los cantones, complementado a su vez con una mayor gestión en la recaudación de recursos económicos por concepto del cumplimiento de obligación tributaria del impuesto predial. En referencia al 2014 y 2015, se denota que si bien el PIB cantonal disminuye la recaudación del impuesto incrementa, es decir, que la gestión realizada por los GAD municipales ha ido mejorando en el tiempo demostrando así un mayor interés por la generación de recursos propios. Sin embrago, se debe enfatizar que el camino a seguir aún es largo y conflictivo, esto responde muchas veces a la presión política y social, ante lo cual la gestión debe demostrar que todo esfuerzo por parte de la ciudadanía se verá recompensado con obras que mejoren su calidad de vida.

\section{Gráfico 5. Evolución del PIB e Impuesto Predial}

$$
2010-2015
$$

\footnotetext{
${ }^{3} \mathrm{El}$ análisis se realiza en el periodo señalado, debido que la información para PIB cantonal se calculó a partir del año 2010.
} 


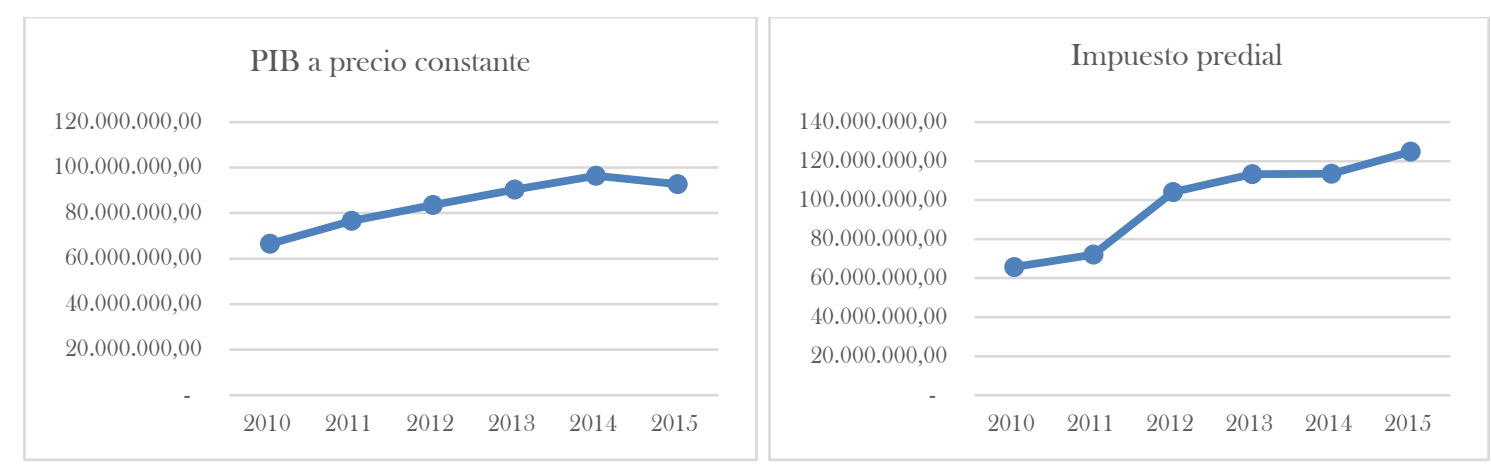

Fuente: Ministerio de Finanzas, Banco Central del Ecuador, 2006 - 2015.

Elaboración: Autores

En el marco de la legislación que respalda las acciones o decisiones que los GAD municipales deben asumir, se encuentra la actualización catastral que cada bienio deben realizar y mediante ordenanza se establecerá la valoración de suelo urbano y rural y la determinación y recaudación del impuesto predial. Es decir, el complemento del catastro es el impuesto predial y sus recursos financian el desarrollo de las ciudades. Si bien es cierto, el impuesto predial ha existido en la gestión de los GAD municipales, aún cuando su implementación ha venido marcada por un simple cumplimiento de normativa, cuando lo óptimo es potenciar este impuesto y lograr conseguir una aplicabilidad saludable.

Las aristas principales para robustecer el impuesto predial parte de contar con:

a. Amplia cobertura catastral, en otras palabras, contar con la circunscripción territorial que pertenece a cada catón y de no ser posible, contar con el mayor número de predios. Esta condición se la cumple a través de un mantenimiento diario del catastro que al final de dos años facilite la plena actualización. Empero, en muchos cantones los recursos

\footnotetext{
4 Área territorial delimitada, donde las características físicas como el uso del suelo, aptitud agrícola y forestal, existencia y disponibilidad de servicios públicos e infraestructura, tienen un nivel de homogeneidad cuantitativa y cualitativa, conceptualizados en los
}

económicos y humanos son escasos, por lo que es recomendable que si no logran tener una amplia cobertura mantengan un castro depurado con registro de información confiable.

b. Buen nivel de avalúos, las valoraciones realizadas a los inmuebles deben estar a valor de mercado o en el mejor de los casos como lo indica la norma 029 de catastros en el art. 66, el avalúo de los inmuebles debe al menos corresponder al $70 \%$ del valor de mercado, es importante también en considerar los criterios valorativos homogéneos ${ }^{4}$ y los ciclos cortos de actualización.

c. Avalúo para el cálculo del impuesto causado, en conformidad a lo expuesto en el COOTAD, el cálculo del impuesto causado se lo realizará con base en la suma de todos los avalúos de predios cuyo titular sea el mismo contribuyente.

d. Registro de gatos tributario, acorde al Código Orgánico de Planificación y Finanzas Públicas en su art. 94, establece que los Gobiernos Autónomos Descentralizados deberán cuantificar y anexar a la proforma

términos y condiciones aplicables a nivel nacional. Constituyen espacios geográficos con características similares, en base al análisis de variables indicadoras. 
presupuestaria correspondiente el registro del gasto tributario.

e. Tarifa, técnicamente considerando número de predios, número de contribuyentes, y dispersión de los avalúos se deberá establecer tarifas proporcionales o progresivas que respeten la banda impositiva establecida en el COOTAD. La diferencia primordial entre estos dos tipos de tarifas radica en identificar si se desea aplicar igualdad o equidad. En el caso de aplicar progresividad deben tener en cuenta que los tramos o grupos a formarse deben ser intrahomogéneos y no tener error de salto ${ }^{5}$.

f. La estrategia de cobranza incide directamente en la eficiencia recaudatoria, al ser mecanismo para maximizar el pago voluntario y efectivizar los créditos morosos. Su fin último es que el valor de los títulos de crédito emitidos por virtud de los tributos y demás ingresos subnacionales se traduzcan en ingresos para los GAD. Las fases de desarrollo de la estrategia deberían enfocarse en:

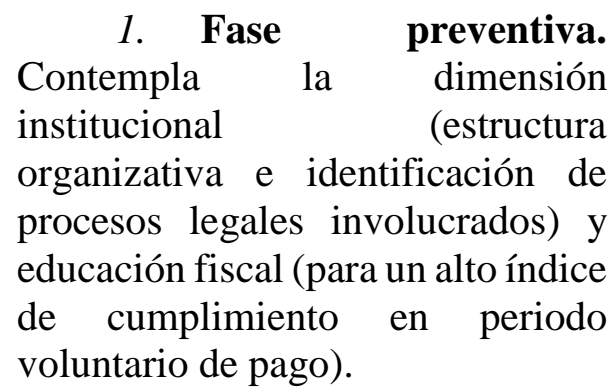

2. Fase

ejecutiva. Contempla el tratamiento, clasificación y priorización de cartera vencida; acciones de cobro persuasivo; y acciones de cobro coactivo.

\section{Gestión tributaria de los impuestos a la actividad económica}

En el marco de las actividades económicas que se desarrollan en cada circunscripción territorial, los GAD municipales tienen la facultad tributaria de exigir el pago de impuestos a las patentes de contribuyentes que están o no obligados a llevar contabilidad y a los activos totales de contribuyentes que por ley están obligados a llevar un registro contable. Por su naturaleza y destino se los analiza en conjunto. En el periodo de estudio se observa que la evolución de su representatividad en el producto interno bruto no tiende al crecimiento o una relativa constancia, por el contrario se identifica el comportamiento en recaudación de estos impuestos es muy irregular, esto puede obedecer al cierre de negocios o locales, al cambio de dirección de los mismos, a la renuencia en el pago, o a la falta de estrategias de cobro por parte del GAD municipal. Con respecto al año 2014-2015 la recaudación incremento significativamente de USD 55 millones de dólares a 393 millones de dólares lo que desemboca una mayor representatividad (Gráfico 6) en referencia al PIB de 0,42\%.

\section{Gráfico 6. Presión fiscal - actividad económica / PIB}

\section{0-2015}

\footnotetext{
${ }^{5}$ El error de salto se lo corrige aplicando la fracción
} básica. 


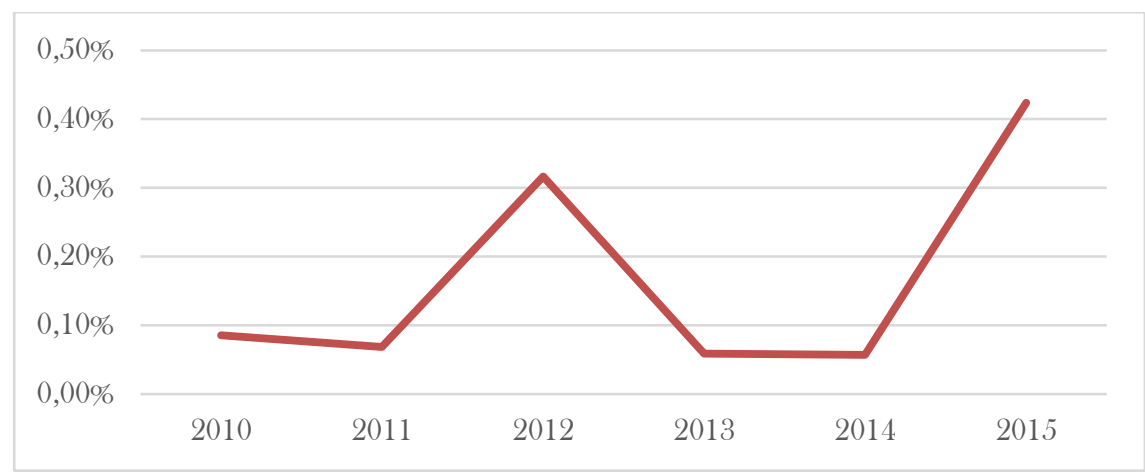

Fuente: Ministerio de Finanzas, Banco Central del Ecuador, 2006 - 2015.

Elaboración: Autores

El enfoque, en la presión fiscal, orienta el resultado hacia una mejor recaudación de los impuestos a patentes y activos totales, pese a la disminución o caída en la producción de bienes y servicios de los cantones, vista a través del PIB. No obstante, el comportamiento de la recaudación de cada uno de los impuestos mencionados y, por ende, de su total, en el transcurso del tiempo sea tan irregular sobre todo porque se gravan a la actividad económica del territorio. Es peculiar que existan decrementos e incrementos tan pronunciados, es indudable también que los locales comerciales como las empresas asentadas en cada territorio puedan dejar de funcionar, $i$ es este el fenómeno que da respuesta a las oscilaciones o es un conjunto de contracciones en la economía nacional que desemboca en fuertes impactos para las finanzas subnacionales? Son estas interrogantes que cada uno de los GAD municipales debe responder para fortalecer y seguir madurando su gestión, con el ánimo de no dejar de percibir los ingresos que por ley les corresponde.

\section{Gráfico 7. Evolución del PIB - Impuestos a las actividades económicas $2010-2015$}

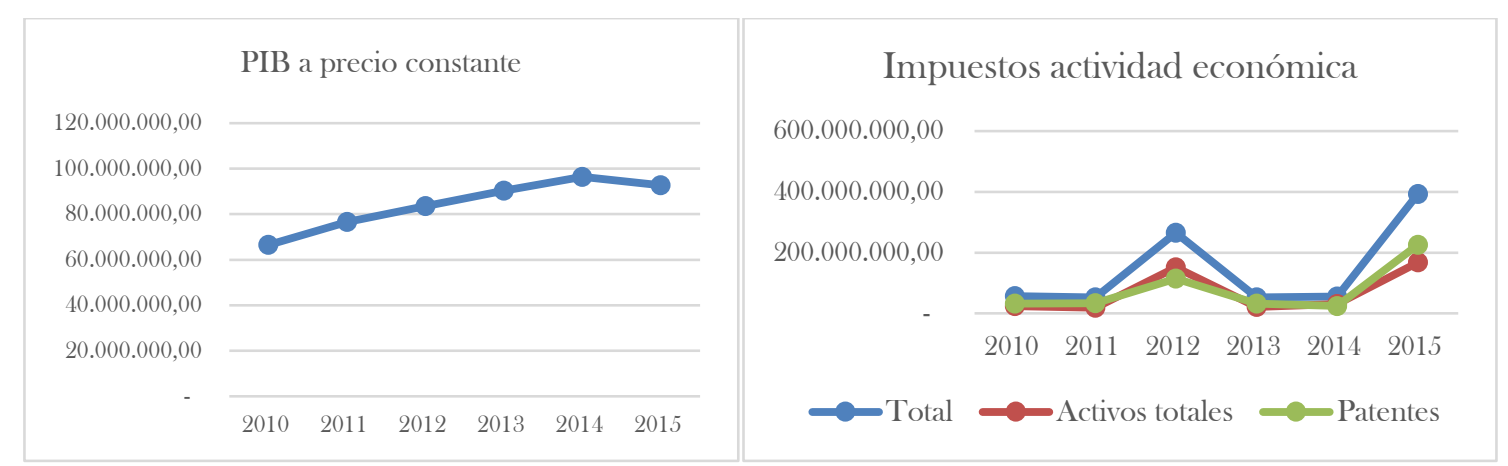

Fuente: Ministerio de Finanzas, Banco Central del Ecuador, 2006 - 2015.

Elaboración: Autores

La gestión tributaria para cada uno de estos impuestos difiere, partiendo desde el sujeto pasivo, la base imponible hasta la tarifa a gravarse por actividad económica. La relevancia de la diferenciación radica en identificar en cuál de los dos tributos existe mayor maniobra de gestión para los GAD municipales, partiendo del hecho que su aplicación va direccionada al patrimonio pero se enfatiza en diferentes niveles de cálculo. 
Bajo esta premisa, la importancia de contar con un catastro de usuarios actualizado y real es fundamental para la gestión de estos tributos.
De ahí surge la necesidad de realizar esfuerzos conjuntos para que los GAD municipales cuenten con un catastro fehaciente.

\section{Cuadro 2. Diferencias básicas entre el los impuestos de patentes y activos totales}

\begin{tabular}{|c|c|c|}
\hline & Patentes & Activos totales \\
\hline Sujeto pasivo & $\begin{array}{l}\text { Personas jurídicas y personas naturales } \\
\text { domiciliadas o con establecimiento en la } \\
\text { respectiva jurisdicción municipal, que } \\
\text { ejerzan permanentemente actividades } \\
\text { económicas que están obligas o no a llevar } \\
\text { contabilidad. }\end{array}$ & $\begin{array}{l}\text { Son las personas naturales, jurídicas, sociedades } \\
\text { nacionales o extranjeras, domiciliadas o con } \\
\text { establecimiento en la respectiva jurisdicción } \\
\text { municipal, que ejerzan permanentemente } \\
\text { actividades económicas y que estén obligados a } \\
\text { llevar contabilidad. }\end{array}$ \\
\hline Base imponible & patrimonio $=$ activo - pasivo & $\begin{array}{c}\text { activos totales }-(\text { pasivos } \\
\text { corrientes }+ \text { pasivos contingentes })\end{array}$ \\
\hline Tarifa & $\begin{array}{l}\text { En la respectiva ordenanza se determina el } \\
\text { valor que se cobrará en cada jurisdicción; } \\
\text { ese valor estará entre USD } 10 \text { y máximo } \\
\text { USD } \\
25000 \text {. }\end{array}$ & USD 1.5 mil del valor de los activos totales \\
\hline
\end{tabular}

Fuente: COOTAD, 2016.

Elaboración: Autores

Identificado las principales divergencias entre los dos impuestos, se deduce que con base en la banda impositiva establecida para patentes, los GAD municipales pueden propender a la obtención de tarifas progresivas en función de quien mayor patrimonio posea, mayor impuesto pague, respondiendo así al principio de equidad. Sin embargo se debe procurar que la implementación de la progresividad no se traduzca en confiscación ni tampoco en contracción del mercado.

\section{FINALES}

\section{CONSIDERACIONES}

El proceso de descentralización en el Ecuador lleva 8 años, y al considerar el índice de dependencia o autonomía como una proxy en la medición del cumplimiento del objeto por el cual se genera una nueva forma de administración, se puede concluir que la tarea original no se ha cumplido. La espera al goteo estatal ha desencadenado grandes paradojas en el sistema de finanzas subnacionales. Pese a la elaboración de diferentes herramientas o instrumentos por parte del Gobierno Central no existe un estudio que haya determinado cuáles son los GAD que, acorde a su estructura y características territoriales, están en condiciones de generar recursos propios, la falencia que se ha generado recae de forma directa en el desarrollo local.

Otro de los principales problemas de la dependencia de los diferentes niveles de gobierno es la concepción de las transferencias realizadas, esto no pretenden desestimar como se realiza la entrega de recursos; por otro lado, son evidentes ciertos problemas encontrados. En el modelo de equidad territorial se genera una fuerte restricción si el GAD (provincial, municipal o parroquial rural) se creó después del año 2010, esto debido a que no percibirá recursos por el monto $\mathrm{A}$, monto que en la mayoría de casos representa el $75 \%$ del total de la transferencia. En lo referente a los ingresos percibidos por nuevas competencias, en el caso de los GAD municipales debe ser divido para 221 administraciones, monto que antes era manejado exclusivamente por el Gobierno Central. Ante ello se debe plantear políticas púbicas que permitan reorientar de mejor forma la distribución de estos ingresos.

La normativa vigente otorga mayor facultad tributaria a los GAD municipales, ante ello y con base en los resultados obtenidos es 
evidente el mayor recaudo en el periodo de estudio y con ello el paulatino incremento de autonomía financiera; por lo tanto, este incremento no se traduce en mayores ingresos, debido a que los nuevos recursos generados son destinados a cubrir la reducción de transferencias por parte del Estado. Ante ello la necesidad de seguir fortaleciendo de forma saludable sus recursos impositivos es primordial, considerando varios principios básicos al que todo sistema tributario debe propender.

Por ejemplo, según Adam Smith (1776), los tributos deben contar con certeza, es decir, los contribuyentes deben identificar con claridad y transparencia desde el hecho generador hasta el pago de la tarifa. Para Wagner (1886), el contar con elasticidad y movilidad de la tarifa permitirá que ante cambios financieros se puedan realizar los ajustes necesarios que garanticen la obtención de recursos, Sommers (s/a) considera también importante el análisis de la capacidad de pago por parte de los contribuyentes, él centra su atención en pago de la tarifa y menciona que

\section{Bibliografía}

Asignaciones para provincias por venta de energía de INECEL (Ley 047), 2002.

Bedón, Gustavo y Guerra, Germán (2012), "Nuevo modelo de Descentralización en el Ecuador a partir de la Constitución 2008", XVII Congreso Internacional del CLAD sobre la Reforma del Estado y de la Administración Pública", Cartagena - Colombia.

Concejo Nacional de Competencias. (2012). "Resolución 006-CNC-2012: Transferencia progresiva de tránsito, transporte y seguridad vial", Registro Oficial nro. 712.

Concejo Nacional de Competencias. (2012). "Resolución 008-CNC-2012: Transferencia de Riego y drenaje", Registro Oficial nro. 509. debe existir los tributos cruzados, es decir, quien cuenta con mayores recursos debe pagar más independientemente de la cantidad de beneficios que reciban, por último Neumark (1994) enfatiza la importancia de confluir los principios más relevantes que respondan a las necesidades de un territorio en específico, permitiendo la captación de recursos fiscales y una mejor redistribución de los ingresos.

La realidad de cada GAD es diversa, el estudio realizado es una aproximación de cómo se encuentran las finanzas subnacionales tributarias, la importancia radica en la generación de más investigaciones que permitan identificar con exactitud en cada circunscripción territorial cuál es la fortaleza tributaria con la que cuentan, para así adoptar medidas que les permita desarrollarla con el fin de obtener una recaudación efectiva que permite afianzar sus finanzas y su capacidad institucional, considerando el estímulo continuo al pago por parte del contribuyente a través del manejo de herramientas de comunicación y socialización que reflejen la labor realizada.

Concejo Nacional de Competencias. (2015). "Reforma a la resolución nro. 006-CNC-2012; Transferencia progresiva de tránsito, transporte y seguridad vial", Registro Oficial nro. 447.

Concejo Nacional de Competencias. (2015). "Resolución 004-CNC-2015: Transferencia de la competencia para preservar, mantener y difundir el Patrimonio Arquitectónico y Cultural", Registro Oficial nro. 514.

Concejo Nacional de Competencias. (2017). "Resolución 003-CNC-2017: Apruébese para los años 2018, 2019, 2010 y 2021 varios ponderadores de los criterios constitucionales para la distribución de los recursos a los GAD provenientes del $21 \%$ ingresos permanentes y $10 \%$ ingresos no permanentes del Presupuesto General del Estado, Registro Oficial nro. 21. 
Código Orgánico de Ordenamiento Territorial Autonomía y Descentralización. (2017).

Código Orgánico de Planificación y Finanzas Públicas. (2016).

Ley Orgánica del Régimen Especial de la Provincia de Galápagos. (2015).

Ley Orgánica para el Ecodesarrollo Regional Amazónico (Ley 010). (2008).

Ministerio de Desarrollo Urbano y Vivienda. (2016). “Acuerdo 029-16: Normas Técnicas Nacionales para el Catastro de bienes; operación y cálculo de tarifas por los servicios técnicos de la Dirección Nacional de Avalúos y Catastros".

Ministerio de Economía y Finanzas, Base de datos 2006-2015.

Montaño, César. (2013). "Descentralización y autonomía fiscal en el Ecuador: bases teóricas y tensiones jurídicas", Revista de Derecho nro. 20, UASB - Ecuador.

Nwmark, Fritz. (1994). "Principios de la imposición".
Secretaría Nacional de Planificación y Desarrollo (2012), "Plan Nacional de Descentralización 2012 - 2015”, Quito.

Secretaría Nacional de Planificación y Desarrollo. (2014). "Informe del estado de transferencia de la competencia de riego y drenaje", Quito.

Secretaría Nacional de Planificación y Desarrollo. (2014). "Modelo de equidad territorial en la provisión de bienes y servicios públicos 2011-2013”, Quito.

Smith, Adam. (1776). "An inqury into he nature and causes of the Wealth of Nations"

Sommers, Harold. (s/a). "Finanzas Públicas e Ingreso Nacional".

Suing, José. (2013). "El Estado de la descentralización fiscal en el Ecuador", Revista de Derecho nro. 20, UASB - Ecuador.

Wagner, Adolfo. (1886). "Finanzwissenschaft: die britische und französische besteuerung in ihrer neuesten entwicklung und gestaltung". 